\title{
Heat transfer analysis of a loop heat pipe with biporous wicks
}

\author{
Chien-Chih Yeh, Chun-Nan Chen, Yau-Ming Chen * \\ Department of Mechanical Engineering, National Taiwan University, Taipei, Taiwan, ROC
}

\section{A R T I C L E I N F O}

\section{Article history:}

Received 15 October 2008

Received in revised form 23 January 2009

Accepted 18 March 2009

Available online 15 May 2009

\section{Keywords:}

Loop heat pipe

Evaporative heat transfer

Biporous wick

Monoporous wick

\begin{abstract}
A B S T R A C T
Because the evaporative heat transfer of a wick structure in a loop heat pipe is exceedingly sensitive to the internal volume fractions of liquid and vapor phases, the purpose of this study was to investigate the evaporative heat transfer of various biporous wick parameters by controlling the particle size of pore former, the pore former content, and the sintering temperature. A statistical experiment was carried out to analyze the evaporative heat transfer of the biporous wicks and to understand the effects of the parameters more effectively. The statistical analysis indicated a clear and strong relationship between the effect of the pore former content and the evaporative heat transfer of a biporous wick. This is because the pore former content had a great influence on the probability of large interconnecting pores and an extended surface area for liquid film evaporation in a biporous wick. Experimental results also showed that, at the sink temperature of $10^{\circ} \mathrm{C}$ and the allowable evaporator temperature of $85^{\circ} \mathrm{C}$, the evaporative heat transfer coefficient of the biporous wick, which reached a maximum value of $64,000 \mathrm{~W} / \mathrm{m}^{2} \mathrm{~K}$, was approximately six times higher than that of the monoporous wick.
\end{abstract}

(c) 2009 Elsevier Ltd. All rights reserved.

\section{Introduction}

The liquid film evaporation in porous media is a very efficient heat transfer method utilized in two-phase heat transport devices such as heat pipes, capillary pumped loops (CPLs), and loop heat pipes (LHPs). More recently, with the increasing demand of thermal management for advanced electronic cooling, the heat-dissipating technologies of these devices have been already more critical.

In 1994 Wolf et al. [1] pointed out that LHPs combine the advantages of both conventional heat pipes and CPLs. In addition, a LHP possesses the following advantages so this device is chosen to be the object of research in this study:

- passive heat transport system - no moving parts;

- a highly efficient design of the inverted meniscus type evaporator;

- a low thermal resistance;

- ability to work reliably in operation;

- ability to operate against gravity;

- self-priming - requires no power input;

- flexible heat transport lines;

- to transport large amounts of heat over long distances with minimal temperature drops;

\footnotetext{
* Corresponding author. Address: Department of Mechanical Engineering, National Taiwan University, No. 1, Sec. 4, Roosevelt Road, Taipei, 10617 Taiwan, ROC. Tel.: +886 2 33662730; fax: +886 223631755.

E-mail address: ymchen@ntu.edu.tw (Y.-M. Chen).
}

A LHP was first invented and developed in the former Soviet Union in 1974 [2]. These researchers have demonstrated LHPs' effectiveness, reliable, and long-term operation in spacecraft thermal control. In the last several decades LHPs have been necessary and widely utilized not only in space but also in ground applications such as electronic cooling, solar heat collector, avionics cooling, air conditioner, refrigeration systems, etc.

The LHP system consists of an evaporator, a condenser, a compensation chamber, a vapor transport line, and a liquid transport line. A wick structure is only localized in the evaporator. A schematic of the LHP system can be found in Fig. 1.

A LHP relies on the surface-tension force of a fine wick structure under application of heat to drive a working fluid. When heat is applied to the evaporator, the liquid is vaporized to generate the inverted menisci at the liquid-vapor interface in the wick; meanwhile, the wick develops the capillary force to transfer the vapor through the vapor line to the condenser. After the vapor is condensed, the capillary force continues to push the liquid back to the evaporator. According to the aforementioned, the main purpose of a wick is to develop the capillary pressure to circulate a working fluid around the loop and to generate the liquid film evaporation. Hence, there is a close relation between the design of a wick structure and the heat transport capability of a LHP.

In recent years, miniature LHPs have been already researched more and more for passive cooling of high-power electronic and optical components. Through the analysis of the total thermal resistance for a miniature LHP, it can be also understood that the total thermal resistance is mainly influenced by the designs of the evaporator and condenser [3]. Because the design of a 


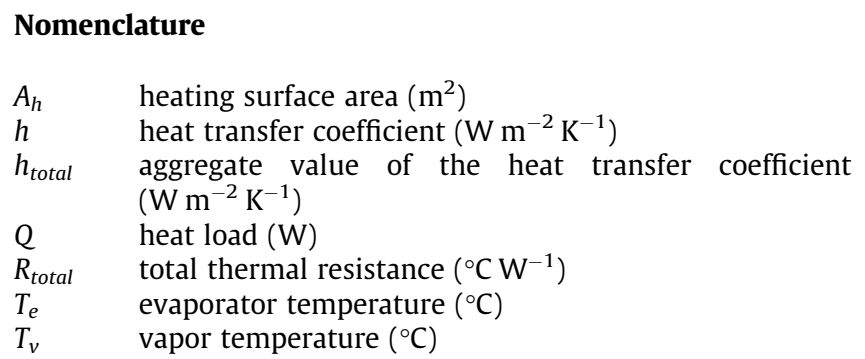

$T_{c} \quad$ condenser temperature $\left({ }^{\circ} \mathrm{C}\right)$

$\begin{array}{ll}\text { Subscripts } \\ c & \text { condenser } \\ e & \text { evaporator } \\ h & \text { heating } \\ \text { total } & \text { total } \\ v & \text { vapor }\end{array}$

condenser is usually determined by the different environments, it will not be discussed here. The evaporator thermal resistance mainly consists of the thermal resistance of the evaporator wall thickness, the contact thermal resistance between the wick outer surface and the evaporator wall, the thermal resistance of a vapor blanket inside the wick, and the film resistance. At high heat fluxes, formerly a monoporous wick was intolerant of boiling and easily occupied by the vapor to form a vapor blanket, leading to raise the thermal resistance. Because the thermal conductivity of a vapor blanket layer is very low, it increases the evaporator temperature. This presents a serious hurdle to using a monoporous wick for removal of high heat fluxes from smaller surfaces. Therefore, how to increase a wick heat flux limit by reducing a vapor blanket inside a wick will be important. To that end, the design of a wick structure is one of the major preoccupations of a miniature LHP. In general, a wick structure design can be classified into the designs of outer vapor grooves and inner wick structure parameters (effective pore radius, porosity, and permeability). They both will affect the amount of the vapor escaped from the wick and the volume fractions of liquid and vapor phases inside a wick. However, with the decreasing evaporator diameter of a miniature LHP, the manufacture of outer vapor grooves on a wick structure has become more difficult.

In order to avoid the foregoing problems, wick structures with bimodal pore size distributions are utilized to improve the heat transport capability of miniature LHPs. The advantages of wick structures with bimodal pore size distributions are that the large pores reduce a vapor blanket layer to impede the returning liquid flow, and that the small pores continue to function as liquid supply routes and increase the evaporative surface area at the same time. In general, bidispersed wicks and biporous wicks can make the wick structures with bimodal pore size distributions.

Early heat transfer experiments of bidispersed wicks can be traced back to Vityaz et al. [4]. They utilized the surface oxidation on sintered copper wick structure to generate the bidispersed wick, which was characterized by a bimodal pore size distribution, as heat pipe wick. The bidispersed wick structure could significantly increase the heat transport capability. Additionally, Konev et al. [5] investigated boiling phenomenon in wick structures and

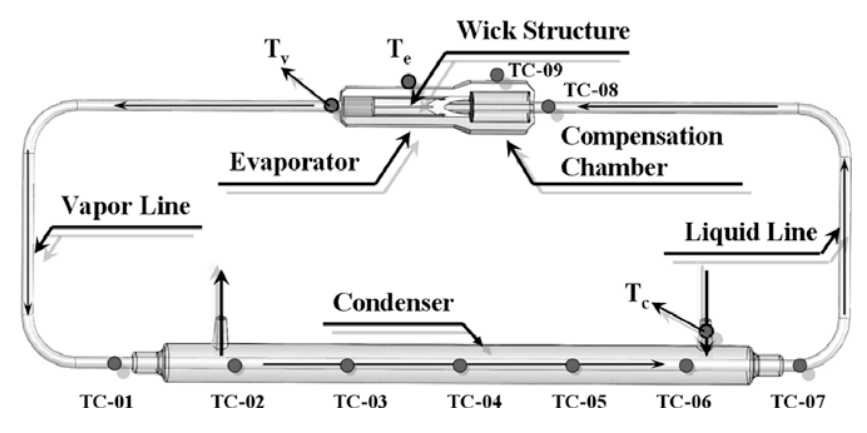

Fig. 1. Schematic of a LHP. pointed out that a bidispersed wick enhances the boiling heat transfer to a greater extent than a monoporous wick. Afterwards, a biporous material was proposed by Rasor and Desplat [6]. Their K-Max consists of a solid biporous material that has exceptional heat transfer properties and is similar to a heat pipe. In addition, they also mentioned that two different types of pore sizes can be existed in a biporous wick like a bidispersed wick. The structural differentiation between a biporous wick and a bidispersed wick was described and illustrated in this literature.

Rosenfeld and North [7] indicated that a bidispersed wick takes advantage of the highly effective heat transfer intrinsic to liquid film evaporation in heat pipe operation. The evaporative characteristic of a bidispersed wick was described particularly and discussed for the potentiality of optics applications. North et al. [8] reported the liquid film evaporation from bidispersed wicks in heat pipe evaporators and explained the improvement of heat transfer due to an extended surface area for evaporating thin film from the bidispersed wick. Additionally, North et al. [9] proposed that the LHP's evaporators with bidispersed wicks are effective to prevent a vapor blanket of the wick and then work at very high heat-flux densities. Nevertheless, there is very limited study on the effect of the bidispersed wick parameters and the relative manufacturing procedures of the bidispersed wick in this study.

In subsequent years Wang and Catton [10-11] carried out numerous studies about the effectiveness of bidispersed wicks for heat pipes. Semenic and Catton [12] proposed the effects of bidispersed wick parameters such as powder size, and cluster size, wick thickness, and liquid feed length for a heat pipe. The results indicated that a capillary pressure of small pores generated by powder size is a dominant parameter.

As reviewed and summarized previous studies, the majority of research in bidispersed wicks has focused on the behavior of vaporization heat transfer in heat pipes. A number of studies have suggested the benefits of bidispersed wicks in pool boiling and heat pipes. However, few studies have been done on the procedure for making the bidispersed wick and the effect of the bidispersed wick parameters in LHPs. However, a biporous wick can provide higher porosity than a bidispersed wick. It cannot only decrease the effect of heat leak through the biporous wick to the compensation chamber in the design of a LHP evaporator with the "inverted meniscus scheme", but also can increase the surface area for liquid film evaporation. In addition, because large pores generated by dissolving the pore formers in biporous wicks are easier to control than those passively formed by collecting the clusters of small porous particles in bidispersed wicks, the effects of various bimodal pore size distributions are demonstrated through biporous wicks in this study.

Because the heat transport capability of a LHP is exceedingly sensitive to a bimodal pore size distribution in the biporous wick, the purpose of this study was to investigate the evaporative heat transfer phenomenon of various biporous wicks in a LHP. A statistical method was used to analyze the evaporative heat transfer of the biporous wicks and to find out the better biporous wick. 
Table 1

Main design parameters of the LHP.

LHP evaporator

Active length (mm)

Outer/Inner diameter $(\mathrm{mm})$

Number of vapor grooves

Vapor line
Total length ( $\mathrm{mm})$

Material

Sintered nickel wick

Pore radius $(\mu \mathrm{m})$

Porosity (\%)

Permeability $\left(\mathrm{m}^{2}\right)$

Outer/inner diameter (mm)

Compensation chamber

Outer/inner diameter ( $\mathrm{mm})$

Length ( $\mathrm{mm})$

Charge mass

Ammonia (g)

Outer/inner diameter ( $\mathrm{mm})$

Length ( $\mathrm{mm}$ )

Liquid line

Outer/inner diameter ( $\mathrm{mm}$ )

Length $(\mathrm{mm})$

65

$15.5 / 12.5$

Aluminum

8

1.5-17

70-85

$10^{-12}-10^{-13}$

$12.5 / 9$

$29 / 24$

118

$6.4 / 5$

470

$6 / 4$

583

Condense

Outer/inner diameter (mm)

Length ( $\mathrm{mm})$

$6.4 / 5$

800
This investigation may lead to a better understanding of how the biporous wick parameters affect the evaporative heat transfer and be important for the related design of wick structures.

\section{Experimental apparatus and procedures}

\subsection{LHP design and test method}

All tests were examined in the same LHP system. Table 1 gives the main design parameters of the LHP. The LHP test bed was placed horizontally to avoid any influence of the gravity force. The LHP evaporator was built with aluminum, and the wick structure was made from nickel powder, which was commercially available and compatible with the ammonia working fluid of the LHP. Other components of the LHP system were built with stainless steels.

All tests were performed under the near ambient environment, and the condenser sink temperature was controlled to $10 \pm 2{ }^{\circ} \mathrm{C}$ by a water cooler. Heat was applied to the evaporator through a copper heater block by a DC power supply (deviation of $\pm 0.5 \%$ ), and the heat input area was $1948 \mathrm{~mm}^{2}$. The thermocouple measurements were recorded and transferred to the computer through a GPIB card. The location of 12 T-type thermocouples (deviation of $\pm 0.2{ }^{\circ} \mathrm{C}$ ) is given in Fig. 1 .

For the heat transport capability of the LHP, the temperature change on the evaporator surface was measured by per $50 \mathrm{~W}$, and the heat load was increased from 50 to $570 \mathrm{~W}$. In general, it is recommended that the surface temperature of common electronic chips shall not exceed $85^{\circ} \mathrm{C}$ [13]. It can be considered as an important reference if loop heat pipes are used in common electronic chips in the future. The heat transport capacity was taken to be a maximum if the evaporator temperature started to exceed $85^{\circ} \mathrm{C}$.

In order to examine the enhancement on the thermal performances for the different wick structures used, the calculation of the heat transfer coefficient in the evaporator will be analyzed. In the present study, the heat transfer coefficient in the evaporator is defined as:

$h=\frac{Q}{A_{h}\left(T_{e}-T_{v}\right)}$

where $Q$ is the heat load, and $A_{h}$ denotes the heating surface area. In addition, $T_{e}$ is the evaporator temperature, and $T_{v}$ is the vapor temperature which is taken as the temperature on the surface of the vapor outlet tube.

The total thermal resistance can be obtained by

$R_{\text {total }}=\frac{T_{e}-T_{c}}{Q}$

where $T_{c}$ is the condenser sink temperature.

An uncertainty analysis carried out on the lines suggested by Kline and McClintock [14] showed that the uncertainty involved in the estimation of the heat transfer coefficient in the evaporator Eq. (1) were $\pm 12 \%$ at low heat fluxes and $\pm 5 \%$ at high heat fluxes, and this involved in the estimation of the total thermal resistance Eq. (2) was within $\pm 2.48 \%$.

\subsection{Method of manufacturing the biporous wick structure}

As a rule, there are two methods to manufacture wick structures with bimodal pore size distributions: consolidation of porous particles (here it is defined as "bidispersed wick") and creation of biporous materials (here it is defined as "biporous wick"). The scanning electron microscopy (SEM) images of two wick structures can be gained from Fig. 2 .

Because large pores generated by dissolving the pore formers in biporous wicks are easier to control than those passively formed by collecting the clusters of small porous particles in bidispersed wicks, the effects of various bimodal pore size distributions are demonstrated through biporous wicks. Biporous wicks and monoporous wicks were made from the same nickel powder as a basic component. A schematic view of the process to produce a biporous wick is illustrated in Fig. 3.

First of all, pore formers $\left(\mathrm{Na}_{2} \mathrm{CO}_{3}\right)$ which had the suitable particle size $(32-48 \mu \mathrm{m}$ or $74-88 \mu \mathrm{m})$ and content ( $20 \%$ by volume or $25 \%$ by volume) were mixed uniformly with filamentary nickel powder. Then, the mixing powder filled into the mold was sintered to manufacture a biporous wick in the furnace. The smaller pores of the biporous wick could be generated by sintering the nickel
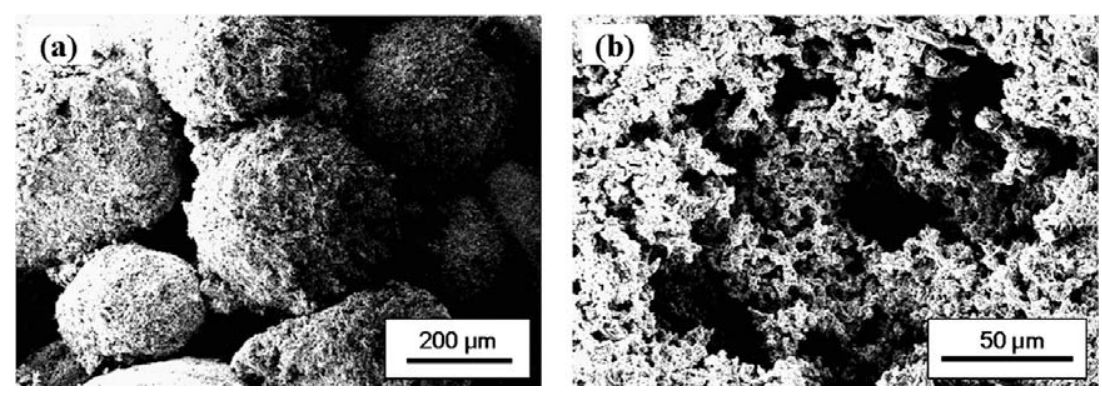

Fig. 2. Photographs of wick structures with bimodal pore size distributions: (a) bidispersed wick and (b) biporous wick. 


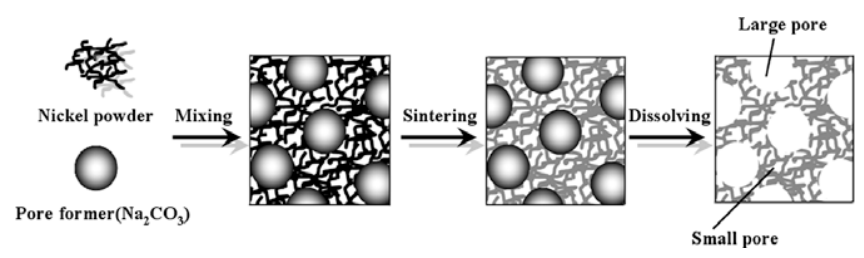

Fig. 3. Schematic view of the process to produce the biporous wicks.

powder; the larger pores of the biporous wick could be formed by dissolving the pore formers after the sintering process. By the way, pore formers were used to control the size and amount of larger pores in the wick. Finally, two different types of pore sizes could be existed in the wick at the same time. The appearance of the biporous wick can be seen in Fig. 4 .

\subsection{Experimental design}

The designs of vapor grooves and wick parameters in the evaporator would be the key impact on the performance of a LHP. In order to differentiate the effects between vapor grooves and wick parameters, the eight axial vapor grooves made on the wick outer surface were fixed. Then, the heat transfer coefficient in the evaporator would be analyzed by only changing the wick parameters.

A statistical experimental design was applied to increase the efficiency of this study and to make the conclusions be valid and objective. The study is conducted following a statistical method using a two-level factorial plan involving three variables (particle size of pore former: $32-48$ and $74-88 \mu \mathrm{m} \mathrm{Na}_{2} \mathrm{CO}_{3}$, pore former content: $20 \%$ by volume and $25 \%$ by volume, and sintering temperature: 650 and $750{ }^{\circ} \mathrm{C}$ ), as observed in Table 2. The experimental design was that of three factors such as particle size of pore former (A), pore former content (B), and sintering temperature (C), each run at two levels. This is a $2^{3}$ factorial design. The variables $A, B$, and $C$ are defined on a coded scale from -1 to +1 (the low and high levels of $\mathrm{A}-\mathrm{C}$ ). Furthermore, in order to consider the curvature effect in the response function, the test for curvature would be performed by adding several center points to the $2^{3}$ factorial design. Finally, the regression model could be represented by the terms of coded factors. For more details, see Montgomery [15].

The heat transfer coefficient change in the evaporator was measured by per $50 \mathrm{~W}$ and the heat load was increased from 50 to $570 \mathrm{~W}$. In these experimental processes, the response variable was the aggregate value of the heat transfer coefficient in the evaporator $\left(h_{\text {total }}\right)$ from 50 to $570 \mathrm{~W}$. This reason was to evaluate the whole heat transfer coefficient, but not the certain one. Then, the

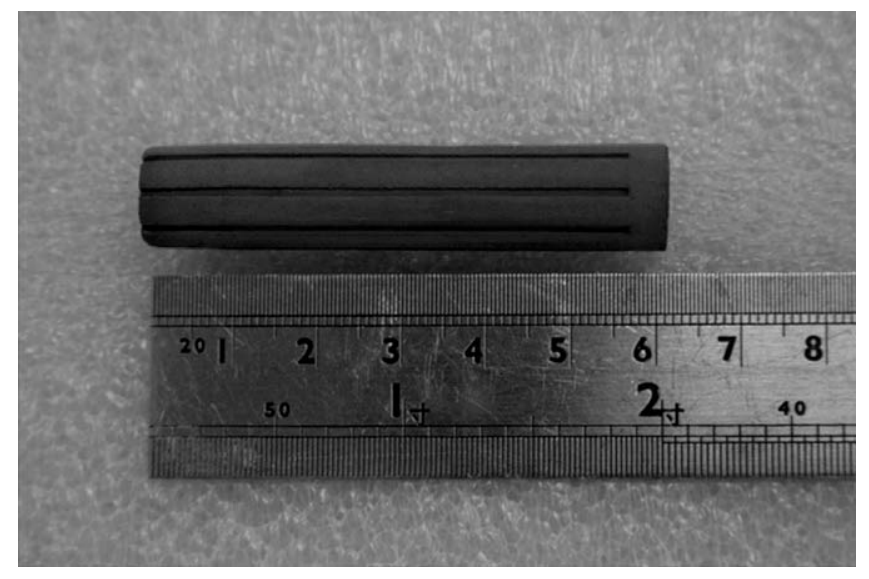

Fig. 4. The appearance of a biporous wick.
Table 2

The selected variables and experimental deign levels used.

\begin{tabular}{lllll}
\hline Variables & Units & Symbol & \multicolumn{2}{l}{ Coded levels } \\
\cline { 3 - 5 } & & & -1 & +1 \\
\hline Particle size of pore former & $\mu \mathrm{m}$ & $\mathrm{A}$ & $32-48$ & $74-88$ \\
Pore former content & $\%$ & $\mathrm{~B}$ & 20 & 25 \\
Sintering temperature & ${ }^{\circ} \mathrm{C}$ & $\mathrm{C}$ & 650 & 750 \\
\hline
\end{tabular}

Note: $A_{\text {code }}=(\mathrm{A}-53) / 21 ; B_{\text {code }}=(\mathrm{B}-22.5) / 2.5 ; C_{\text {code }}=(\mathrm{C}-700) / 50$.

experimental results identified and investigated by the statistical software (DESIGN-EXPERT software) were analyzed to find the region of the optimal parameters.

According to the experimental design with three independent variables (particle size of pore former, pore former content, and sintering temperature) and two levels of each variable, a $2^{3}$ design augmented with three center points yielded a total of 11 runs. The test results of eleven biporous wicks, one monoporous wick, and two confirmation experiments are listed in Table 3.

\section{Results and discussion}

\subsection{Statistical analyses of biporous wicks}

The heat transfer coefficient data were entered into the design matrix (Table 3 ) planned by the statistical software to determine the significant variables. This method allows establishing a statistical relationship between experimental variables and the response $\left(h_{\text {total }}\right)$. Then, a regression analysis is carried out to develop a bestfit model to the experimental data. It can be used to generate response surface plots [15].

In order to reduce the insignificant model terms, the effect estimate was first performed to improve the model. Table 4 summarizes the effect estimates and sums of squares. The percent contribution is often effective guide to the relative importance of each model term. It is noteworthy that the main effects of $A$ (15.59\%), B (76.35\%), and the AB interaction (4.19\%) really dominated this process, accounting for over $96 \%$ of the total variability.

The other $C, A C, B C$, and $A B C$ variables accounted for less than $4 \%$ can be ignored. The analysis of variance (ANOVA) in Table 5 , which illustrates the output following removal of the nonsignificant terms, may be used to confirm the magnitude of these effects and reveal the result of the test of significance of factors and interactions for the $h_{\text {total }}$.

When $p$-value (probability value) of one term is more than 0.05 (a specified significant level), indicating that this is insignificant at the $95 \%$ confidence level and so that term must be discarded. After discarding insignificant terms, Table 5 illustrates that the regression model was significant $(F$-value $=69.50, p$-value $<0.05)$. The main effects of $A, B$, and the $A B$ interaction were significant (all have small $p$-values); thus, $A, B$, and $A B$ can be taken as significant factors at a confidence level of $95 \%$. The curvature in the design space was not significant relative to the noise $(F$-value $=2.39$, $p$-value $>0.05$ ). Therefore, the assumption of linearity over the region of exploration was adequate for the regression model.

The regression model equation describing this relationship in terms of coded factors was as follows:

$h_{\text {total }}=274.67-30.85 A_{\text {code }}+68.26 B_{\text {code }}-15.99 A_{\text {code }} B_{\text {code }}$

A regression model for predicting the $h_{\text {total }}$ was established by the statistical software, which $R^{2}$ was 0.9720 and $R_{\text {adj }}^{2}$ was 0.9580 . These indicated that the model would be expected to explain the experimental data very well. 
Table 3

Properties of the wicks tested.

\begin{tabular}{|c|c|c|c|c|c|c|c|c|c|c|c|c|c|c|c|c|c|}
\hline \multirow{2}{*}{$\begin{array}{l}\text { Sample } \\
\text { Biporous } \\
\text { wick }\end{array}$} & \multicolumn{4}{|c|}{ Experimental design variables } & \multicolumn{12}{|c|}{ Heat transfer coefficient $\left(\mathrm{kW} \mathrm{m} \mathrm{m}^{-2} \mathrm{~K}^{-1}\right)$} & \multirow{2}{*}{ 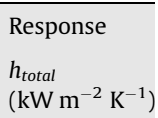 } \\
\hline & $\begin{array}{l}\text { NPS } \\
(\mu \mathrm{m})\end{array}$ & $\begin{array}{l}\text { A } \\
(\mu \mathrm{m})\end{array}$ & $\begin{array}{l}\text { B } \\
\text { (\%) }\end{array}$ & $\begin{array}{l}\mathrm{C} \\
\left({ }^{\circ} \mathrm{C}\right)\end{array}$ & $50 \mathrm{~W}$ & $100 \mathrm{~W}$ & $150 \mathrm{~W}$ & $200 \mathrm{~W}$ & $250 \mathrm{~W}$ & $300 \mathrm{~W}$ & $350 \mathrm{~W}$ & $400 \mathrm{~W}$ & $450 \mathrm{~W}$ & $500 \mathrm{~W}$ & $550 \mathrm{~W}$ & $570 \mathrm{~W}$ & \\
\hline 1 & 3 & $32-48$ & 20 & 650 & 9.51 & 15.11 & 15.41 & 18.02 & 19.76 & 20.28 & 22.76 & 22.83 & 20.10 & 14.85 & 15.61 & 15.17 & 209.40 \\
\hline 2 & 3 & $74-88$ & 20 & 650 & 6.94 & 8.71 & 12.43 & 12.68 & 15.47 & 13.52 & 13.03 & 14.37 & 22.89 & 22.33 & 22.25 & 22.52 & 187.13 \\
\hline 3 & 3 & $32-48$ & 25 & 650 & 8.56 & 19.02 & 14.54 & 14.27 & 37.77 & 42.81 & 99.88 & 46.70 & 39.85 & 41.42 & 24.57 & 15.66 & 405.04 \\
\hline 4 & 3 & $74-88$ & 25 & 650 & 12.23 & 13.17 & 19.26 & 23.35 & 24.23 & 24.08 & 33.29 & 42.81 & 34.50 & 26.48 & 18.23 & 13.07 & 284.69 \\
\hline 5 & 3 & $32-48$ & 20 & 750 & 10.27 & 11.17 & 12.04 & 12.84 & 19.17 & 21.40 & 23.97 & 28.15 & 27.85 & 20.55 & 23.54 & 22.18 & 233.13 \\
\hline 6 & 3 & $74-88$ & 20 & 750 & 8.03 & 11.17 & 13.06 & 14.47 & 14.43 & 17.12 & 20.20 & 22.83 & 22.66 & 17.59 & 16.24 & 18.19 & 195.98 \\
\hline 7 & 3 & $32-48$ & 25 & 750 & 13.52 & 22.33 & 22.01 & 22.33 & 25.68 & 32.10 & 42.81 & 64.21 & 52.53 & 29.86 & 24.57 & 22.52 & 374.48 \\
\hline 8 & 3 & $74-88$ & 25 & 750 & 8.86 & 16.57 & 16.75 & 16.57 & 18.09 & 34.24 & 42.81 & 42.81 & 42.03 & 38.33 & 19.09 & 11.35 & 307.48 \\
\hline 9 & 3 & $53-62$ & 22.5 & 700 & 9.51 & 13.88 & 16.05 & 19.76 & 21.40 & 24.08 & 29.47 & 35.43 & 27.85 & 23.78 & 19.76 & 19.39 & 260.36 \\
\hline 10 & 3 & $53-62$ & 22.5 & 700 & 11.67 & 16.57 & 17.12 & 20.55 & 22.14 & 24.46 & 26.83 & 28.54 & 23.11 & 20.55 & 17.23 & 17.22 & 245.99 \\
\hline 11 & 3 & $53-62$ & 22.5 & 700 & 11.17 & 16.05 & 17.51 & 21.40 & 24.70 & 25.26 & 23.97 & 32.10 & 28.89 & 23.35 & 24.57 & 21.53 & 270.50 \\
\hline \multicolumn{18}{|c|}{ Confirmation experiments } \\
\hline 12 & 3 & $20-32$ & 25 & 750 & 17.12 & 16.57 & 16.75 & 20.55 & 27.92 & 34.24 & 41.81 & 68.49 & 53.76 & 38.91 & 28.83 & 26.62 & 391.56 \\
\hline 13 & 3 & $124-149$ & 25 & 750 & 12.23 & 14.27 & 15.41 & 18.68 & 21.40 & 17.92 & 17.29 & 17.12 & 15.72 & 15.29 & 14.56 & 15.83 & 195.72 \\
\hline \multicolumn{18}{|c|}{ Monoporous wick } \\
\hline 14 & 3 & - & - & 750 & 10.70 & 12.53 & 9.51 & 9.78 & 10.44 & 10.63 & 9.08 & 8.39 & 8.44 & 7.44 & & & \\
\hline
\end{tabular}

Note: NPS, nickel powder size; A, particle size of pore former; B, pore former content; C, sintering temperature.

\subsection{The effects of the biporous wick parameters}

From Eq. (3), one can see that the effect of the particle size of pore former (negative algebraic sign for factor A) was negative; that is, decreasing the particle size of pore former improved the $h_{\text {total }}$. On the other hand, positive trend was observed with the pore former content (factor $B$ ). Moreover, the interaction between particle size of pore former and pore former content (AB interaction) negatively affected the $h_{\text {total }}$. It is important to emphasize that the sintering temperature (factor $\mathrm{C}$ ) within the studied range $\left(650-750{ }^{\circ} \mathrm{C}\right)$ did not obviously affect the $h_{\text {total }}$.

It can be used to generate the response surface plot according to Eq. (3). Fig. 5 presents the response surface and contour plot for the $h_{\text {total }}$ obtained from the regression model. The contour plot displayed that a direction orientation is dominated by decreasing $\mathrm{A}$ and increasing B, the $h_{\text {total }}$ will be higher. Obviously, the effect of $\mathrm{B}$ was more than that of $\mathrm{A}$. The better $h_{\text {total }}$ of the biporous wick (Sample3 or Sample7) tended to the lower level of A (32-48 $\mu \mathrm{m})$, the higher level of $B$ ( $25 \%$ by volume), and less $A B$ interaction. This probably indicated that the probability of large interconnecting pores in a biporous wick can be improved to form more vapor transport channels by increasing $B$. It will influence not only the volume fractions of liquid and vapor phases but also a higher permeability. Besides, decreasing A can generate more number of large pores and the extended surface area for the liquid film evaporation in the same pore former content. This information provides a direction of the potential improvement.

According to Eq. (3), the two largest coefficient estimates are $A=30.85$ and $B=68.26$. Although the effect of $B$ is more than that

Table 4

Effect estimate.

\begin{tabular}{lrrl}
\hline Factor & $\begin{array}{l}\text { Stdized } \\
\text { effect }\end{array}$ & $\begin{array}{l}\text { Sum of } \\
\text { squares }\end{array}$ & $\begin{array}{l}\text { Percent } \\
\text { contribution }\end{array}$ \\
\hline $\begin{array}{l}\text { A-particle size of pore } \\
\text { former }\end{array}$ & -61.69 & 7611.81 & 15.59 \\
B-pore former content & 136.52 & 37274.82 & 76.35 \\
C-sintering temperature & 6.20 & 76.94 & 0.16 \\
AB & -31.98 & 2045.91 & 4.19 \\
AC & 9.62 & 184.98 & 0.38 \\
BC & -10.09 & 203.44 & 0.42 \\
ABC & 17.06 & 581.96 & 1.19 \\
Curvature & -16.41 & 538.86 & 1.10 \\
\hline
\end{tabular}

of $A$, the strength limit of a biporous wick will not allow exceeding the higher level of $B$ ( $25 \%$ by volume). On the other hand, the lower level of $A(32-48 \mu \mathrm{m})$ can continue to be decreased to around 20$32 \mu \mathrm{m}$ (the current sieve limitation). In other words, the optimal parameters of the biporous wick may be expected to be located near $25 \%$ by volume for the pore former content and $20-32 \mu \mathrm{m}$ for the particle size of pore former.

\subsection{Confirmation experiments}

The experimental and predicted values were compared in order to determine the validity of the model and confirm whether the relative important factors were ignored. Hence, two confirmation experiments are planned to confirm the results in Table 6 . These findings appeared that the errors between the experimental and predicted values were all less than $7 \%$. They demonstrated the predicted model was valid and adequate.

\subsection{Heat transfer performances of monoporous and biporous wicks}

In order to examine the heat transfer performances for the different wick structures used, one monoporous wick (Sample14), the better and worse biporous wicks (Sample7 and Sample2) were chosen particularly to discuss here. The parameters of all wick

Table 5

Analysis of variance.

\begin{tabular}{|c|c|c|c|c|c|c|}
\hline Source & & $\begin{array}{l}\text { Sum of } \\
\text { squares }\end{array}$ & $\begin{array}{l}\text { Degrees of } \\
\text { freedom }\end{array}$ & $\begin{array}{l}\text { Mean } \\
\text { square }\end{array}$ & $F$-Value & $p$-Value \\
\hline Model & & 46932.53 & 3 & 15644.18 & 69.50 & $<0.0001$ \\
\hline \multicolumn{7}{|l|}{ Intercept } \\
\hline A & & 7611.81 & 1 & 7611.81 & 33.82 & 0.0011 \\
\hline B & & 37274.82 & 1 & 37274.82 & 165.59 & $<0.0001$ \\
\hline $\mathrm{AB}$ & & 2045.91 & 1 & 2045.91 & 9.09 & 0.0236 \\
\hline Curvature & & 538.86 & 1 & 538.86 & 2.39 & 0.1728 \\
\hline Residual & & 1350.60 & 6 & 225.10 & & \\
\hline Lack of fit & & 1047.32 & 4 & 261.83 & 1.73 & 0.3987 \\
\hline Pure error & & 303.28 & 2 & 151.64 & & \\
\hline $\begin{array}{l}\text { Corrected } \\
\text { total }\end{array}$ & & 48822.00 & 10 & & & \\
\hline$R^{2}$ & 0.9720 & & & & & \\
\hline$R_{\mathrm{Adj}}^{2}$ & 0.9580 & & & & & \\
\hline
\end{tabular}




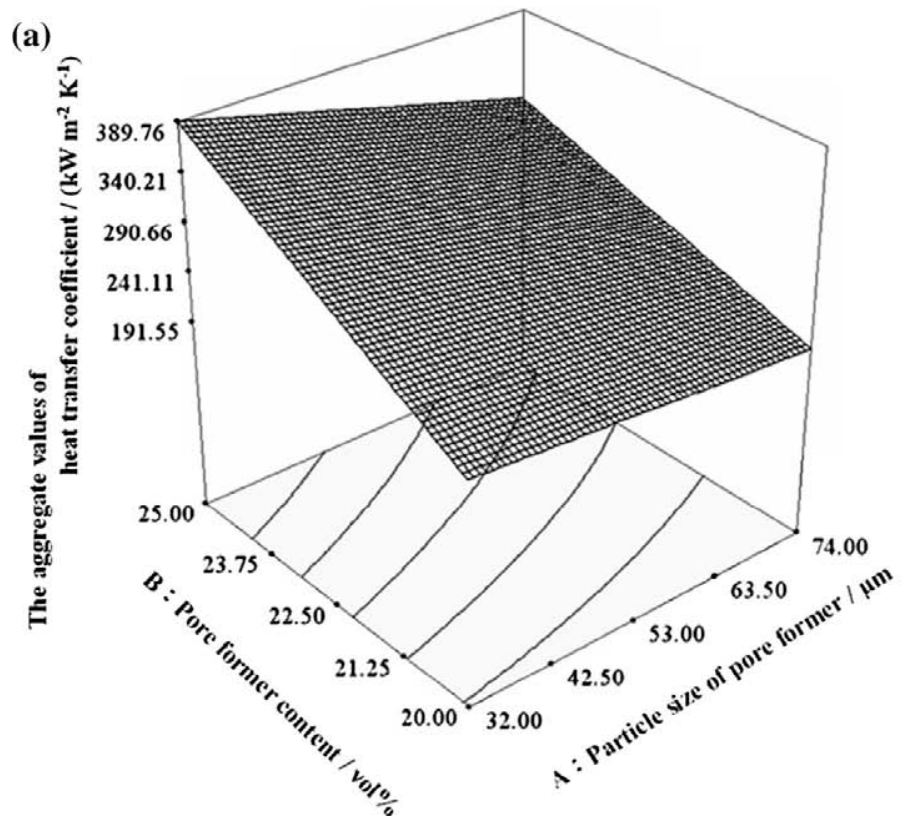

(b) The aggregate values of heat transfer coefficient / $\left(\mathrm{kW} \mathrm{m}^{-2} \mathrm{~K}^{-1}\right)$

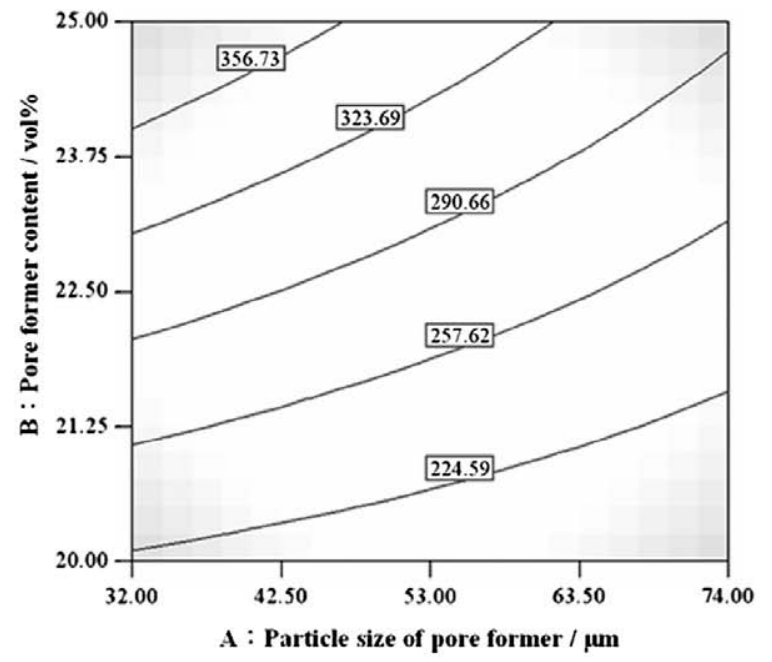

Fig. 5. Response surfaces and contour plot of the $h_{\text {total }}$ : (a) Response surface and (b) contour plot.

Table 6

Comparison of predicted and experimental values.

\begin{tabular}{llllll}
\hline Sample & $\begin{array}{l}\text { Particle size } \\
\text { of pore } \\
\text { former }(\mu \mathrm{m})\end{array}$ & $\begin{array}{l}\text { Pore former } \\
\text { content } \\
(\mathrm{vol} \%)\end{array}$ & $\begin{array}{l}\text { Predict value } \\
\text { of } h_{\text {total }}(\mathrm{kW} \\
\left.\mathrm{m}^{-2} \mathrm{~K}^{-1}\right)\end{array}$ & $\begin{array}{l}\text { Experiment } \\
\text { value of } \\
h_{\text {total }}\left(\mathrm{kW} \mathrm{m}^{-2} \mathrm{~K}^{-1}\right)\end{array}$ & Error (\%) \\
\hline 12 & $20-32$ & 25 & 416.52 & 391.56 & 6.37 \\
13 & $124-149$ & 25 & 184.56 & 195.72 & 5.70 \\
\hline
\end{tabular}

structures are explicitly listed in Table 3. The experimental results are described below.

Sample14 (monoporous wick): the temperature difference $\left(T_{e}-\right.$ $T_{v}$ ) of Sample14 increases linearly when the heat flux increases, as shown in Fig. 6. Accordingly, the heat transfer coefficient of Sample14 does not change very much with the increase of applied heat flux and is approximate $10,000 \mathrm{~W} / \mathrm{m}^{2} \mathrm{~K}$ in Fig. 7. This is due to the fact that evaporative heat transfer was dominated by conduction through the wick and evaporation from the meniscus surface area of the wick structure. Consequently, the curve of Sample14 is like a linear shape in Fig. 6.

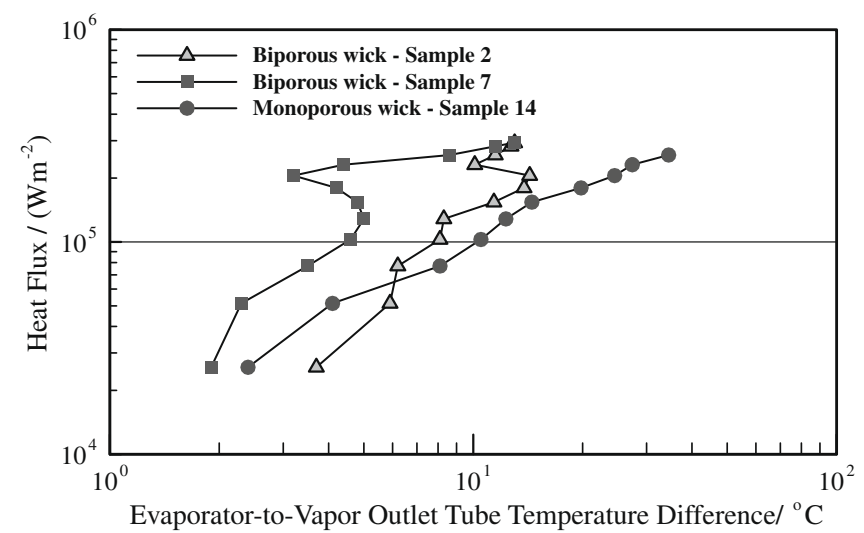

Fig. 6. Evaporator-to-vapor outlet tube temperature difference vs. applied heat flux.
In addition, Figs. 8 and 9 present that, at the sink temperature of $10^{\circ} \mathrm{C}$ and the allowable evaporator temperature of $85^{\circ} \mathrm{C}$, the maximum heat transfer capacity of Sample14 is equal to $350 \mathrm{~W}$ and the minimum total thermal resistance is equal to $0.22^{\circ} \mathrm{C} / \mathrm{W}$.

Sample7 (biporous wick): heat transfer from the heater to the liquid-vapor interface in a biporous wick is a combination of conduction, convection, boiling, and evaporation. At various heat fluxes, the heat transfer performance will be dominated by the different modes of heat transfer. The result of Sample7 reflected in Fig. 6 represents that the evaporative heat transfer curve is almost like an S-shape and can be divided into three different regions. This concept is a similar explanation mentioned for a bidispersed wick by Rosenfeld and North [7].

The first region (below $128.4 \mathrm{~kW} / \mathrm{m}^{2}$ ) reveals that there is an almost linear relationship between the temperature difference and heat flux. Because the evaporation phenomenon only occurs on the surface area of the wick structure at low heat fluxes, the heat transfer is mainly dominated by the conductive mode. In this case,

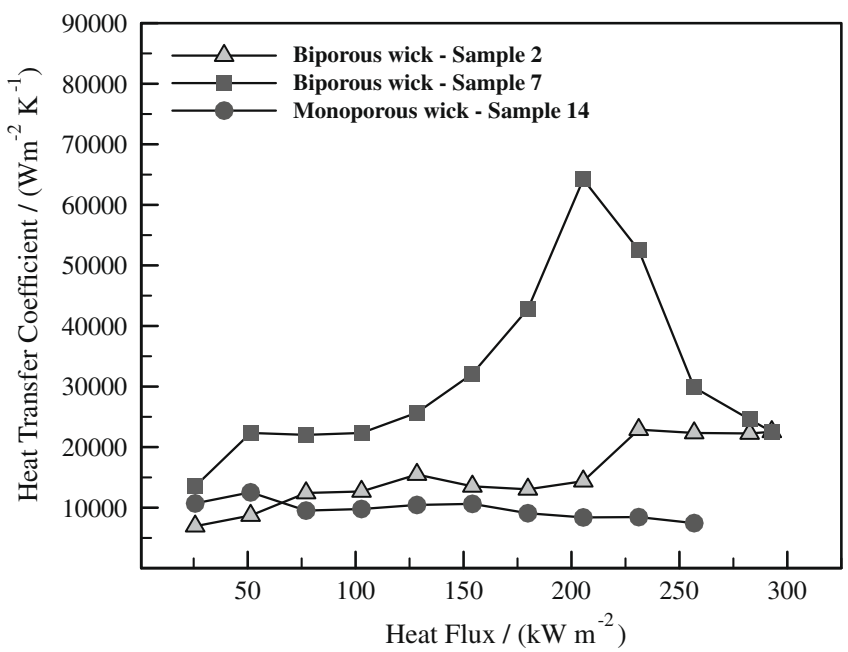

Fig. 7. Evaporative heat transfer coefficient vs. applied heat flux. 


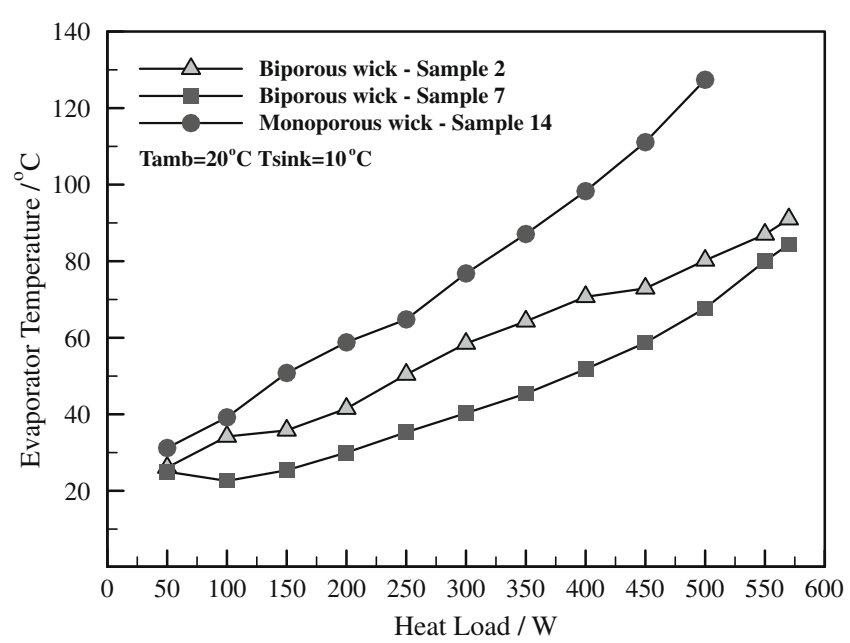

Fig. 8. Evaporator temperature vs. applied heat load.

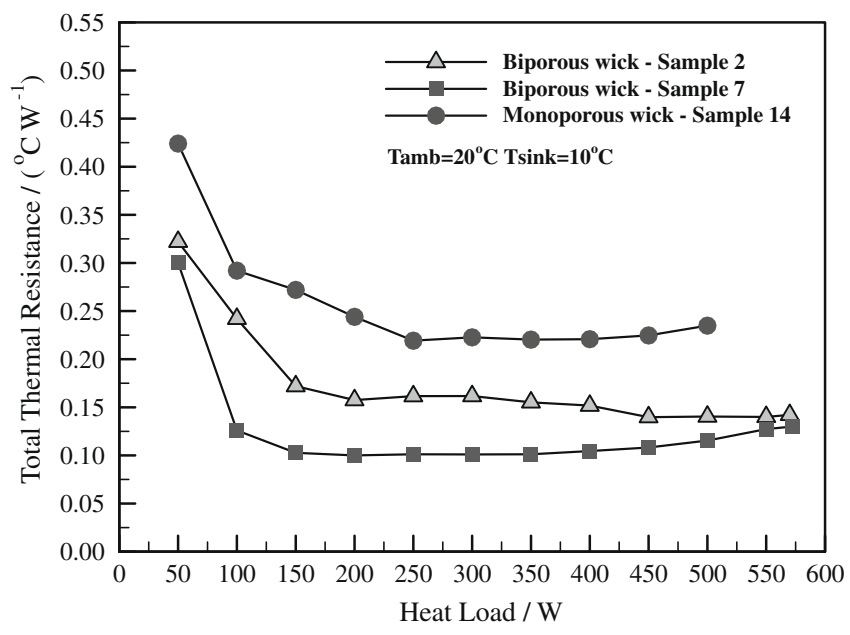

Fig. 9. Total thermal resistance vs. applied heat load.

there is only a small amount of vapor generated and the large pores are still filled with the liquid, as observed in Fig. 10a.

The second region (128.4-205.5 $\mathrm{kW} / \mathrm{m}^{2}$ ) presents that the temperature difference decreases with the increase of applied heat flux, and the evaporative heat transfer curve swings back. In this region the evaporative heat transfer coefficient reaches rapidly a maximum value of $64,000 \mathrm{~W} / \mathrm{m}^{2} \mathrm{~K}$, is higher in the whole range of heat fluxes in Fig. 7. The result could be explained by the liquid-vapor interface in a biporous wick. With the increase of applied heat flux, the vapor will preferentially occupy the large pores to form the vapor pathways. Consequently, the evaporating menisci in a biporous wick include two parts: inverted menisci in small and large pores. As can be seen in Fig. 10b, this is due to the effect that the vapor pathways lead to an extended surface area for liquid film evaporation, and the small pores continue to function as liquid supply routes in the biporous wick.

The third region (above $205.5 \mathrm{~kW} / \mathrm{m}^{2}$ ) starts when vapor pathways develop completely and the liquid cannot be supplied sufficiently by the small pores. The temperature difference grows sharply with the increase of applied heat flux because the dryout starts to occur in the wick in Fig. 10c.

According to the aforementioned, the heat transfer coefficient of Sample7, which reaches a maximum value of $64,000 \mathrm{~W} / \mathrm{m}^{2} \mathrm{~K}$, is approximately six times higher than that of Sample14 in Fig. 7. As observed in Figs. 8 and 9, the experimental results show that, at the sink temperature of $10^{\circ} \mathrm{C}$ and the allowable evaporator temperature of $85^{\circ} \mathrm{C}$, Sample7 reaches $570 \mathrm{~W}$ and the minimum total thermal resistance is $0.10^{\circ} \mathrm{C} / \mathrm{W}$. The heat transport capability of Sample7 is better than that of Sample14 for $350 \mathrm{~W}$ and $0.22{ }^{\circ} \mathrm{C} / \mathrm{W}$. Furthermore, it is important to emphasize that the condenser's design in the research limits the experimental results. They can be expected to gain the higher heat transport capability if the active surface of the condenser is improved.

In order to provide a better understanding of the difference between a monoporous wick (Sample14) and a biporous wick (Sample7), the porous structure analysis was performed by SEM images. According to Fig. 11, the porosity and permeability of Sample14 with a narrow pore size distribution are lower than those of Sample7. With the increase of applied heat flux, the vapor of Sample14 would accumulate gradually to form a vapor blanket between the wick and evaporator wall due to the narrow pore size distribution in Fig. 11a. This not only increased the thermal resistance but also reduced the intensity of heat exchange in the evaporative zone. In contrast, Sample7 obviously has two principal pore size distributions and large interconnecting pores in Fig. 11b. The large pores of Sample7 not only made the vapor easily escape from the wick but also enhanced the evaporating menisci area in the small pores. Therefore, the probability of large interconnecting pores in a biporous wick is of decisive importance.

Sample2 (biporous wick): the temperature difference of Sample2, slight like an S-shape, almost appears to rise linearly with the increase of applied heat flux as that of Sample14 in Fig. 6. The evaporative heat transfer curve of Sample2 seems to be a linear shape as that of a monoporous wick (Sample14) in Fig. 7. The most obvious explanation is due to the effect of the pore former content from the statistical analysis results. With the decrease of the pore former content, the probability of large interconnecting pores in a biporous wick will be decreased. The large pores were easy to form

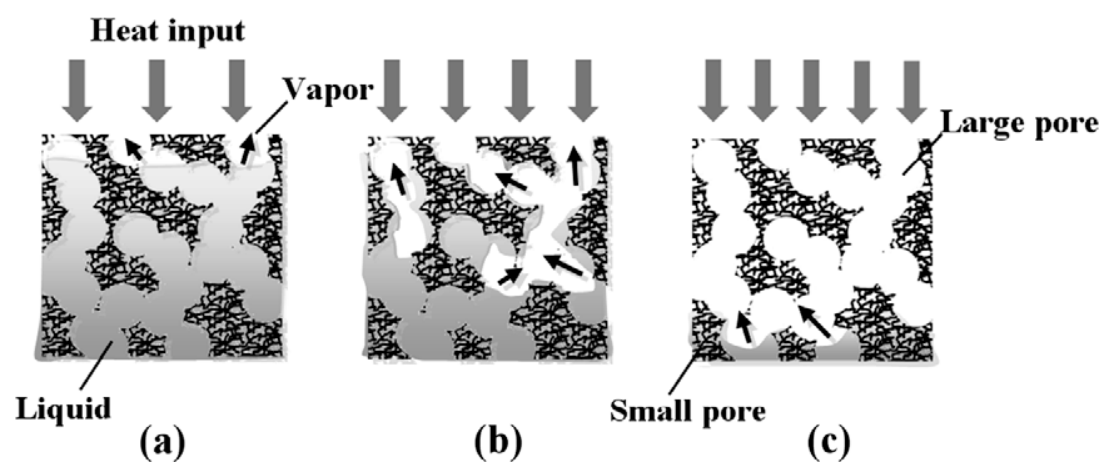

Fig. 10. Schematic diagram illustrating three evaporative models of a biporous wick: (a) the first region, (b) the second region and (c) the third region. 

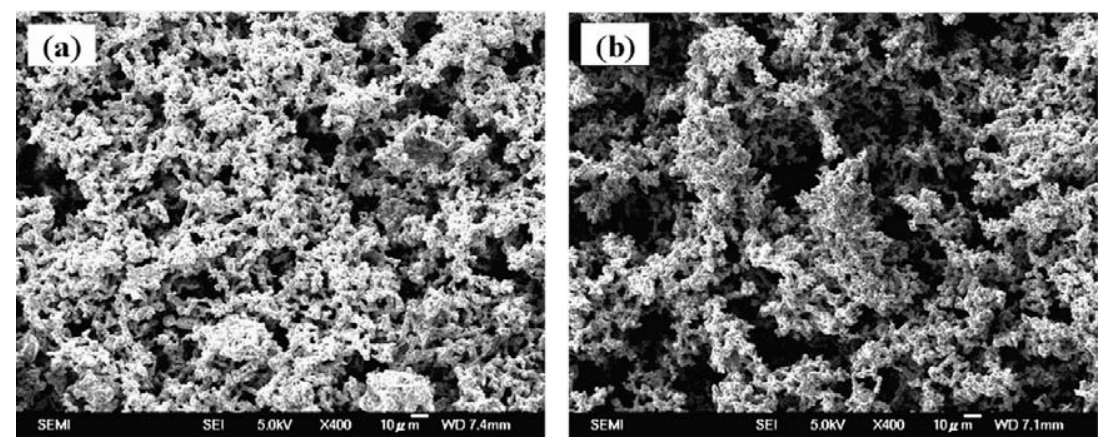

Fig. 11. SEM $(400 \times)$ images of the wick structures: (a) monoporous wick-Sample14 and (b) biporous wick-Sample7.

the isolated ones in Sample2, and thus the increase of liquid film evaporation was limited. At the same time, few amounts of the other large pores on the surface of the wick became the effect of outer vapor grooves. For this reason, the evaporative heat transfer coefficient of Sample2 is better than that of a monoporous wick (Sample14) in Fig. 7.

Furthermore, since the probability of large interconnecting pores for Sample7 was higher than that of Sample2, the vapor pathways of Sample7 were easy to lead to an extended surface area for liquid film evaporation. Perhaps the results can be conjectured why the evaporative heat transfer curve of a biporous wick (Sample7) is similar to that of a bidispersed wick [9-11]. Because a bidispersed wick is made of clusters of small porous particles, the probability of large interconnecting pores for a bidispersed wick is high between the clusters. However, the clusters must be nice spheres, or else the probability of large interconnecting pores for a bidispersed wick will be low. Further research has been pursued to examine the correlation between biporous wicks and bidispersed wicks.

As summarized above, the evaporative heat transfer curve of a wick structure may be determined to be like that of a monoporous wick or a biporous wick by the probability of large interconnecting pores and an extended surface area for liquid film evaporation. This is an important relationship between a monoporous wick and a biporous wick.

On the whole, the experimental results have demonstrated that the biporous wicks can be practically implemented to increase the heat transfer coefficient in the evaporator and provide adequate results. With the increase of demand for high performance miniature LHPs, biporous wicks cannot only improve the heat transfer capability but also be advantageous to simplify and replace the manufacture number of outer vapor grooves on a wick structure. For passive cooling of high-power electronic and optical components, it will be an efficient and simple approach.

\section{Conclusions}

In this paper, the experimental results showed the evaporative heat transfer characteristics of the monoporous and biporous wicks, and the statistical analysis results demonstrated that the effects of various biporous wick parameters on the evaporative heat transfer coefficient. Experimental results of this study lead to the following conclusions:

1. According to the statistical analysis results, the main effects of the particle size of pore former and the pore former content, and the interaction between particle size of pore former and pore former content were significant factors. In contrast, the effect of the sintering temperature was not significant within the studied range $\left(650-750^{\circ} \mathrm{C}\right)$.
2. The statistical analysis indicated that the better parameters of the biporous wick tended to the lower level of particle size of pore former $(32-48 \mu \mathrm{m})$ and the higher level of pore former content ( $25 \%$ by volume). Moreover, the optimal parameters of the biporous wick were approximately located near $20-32 \mu \mathrm{m}$ for the particle size of pore former and $25 \%$ by volume for the pore former content.

3. It is noteworthy that there was a clear and strong relationship between the effect of pore former content and the evaporative heat transfer of a biporous wick. When the pore former content was less, the large pores were easy to form the isolated ones. Few amounts of the other large pores on the wick surface became the effect of outer vapor grooves. For this reason, the evaporative heat transfer of the biporous wick appeared to be like that of a monoporous wick. If the pore former content was more, the evaporative heat transfer of the biporous wick would be dominated by the probability of large interconnecting pores and an extended surface area for liquid film evaporation.

4. At the sink temperature of $10^{\circ} \mathrm{C}$ and the allowable evaporator temperature of $85^{\circ} \mathrm{C}$, the maximum heat transport capability is equal to $570 \mathrm{~W}$ for the better biporous wick and $350 \mathrm{~W}$ for the monoporous wick, and the minimum value of the total thermal resistance is $0.10^{\circ} \mathrm{C} / \mathrm{W}$ and $0.22^{\circ} \mathrm{C} / \mathrm{W}$, respectively. In addition, the evaporative heat transfer coefficient of the better biporous wick, which reaches a maximum value of $64,000 \mathrm{~W} /$ $\mathrm{m}^{2} \mathrm{~K}$, is approximately six times higher than that of the monoporous wick.

\section{References}

[1] D.A. Wolf, D.M. Ernst, A.L. Phillips, Loop heat pipes-their performance and potential, SAE Paper No. 941575.

[2] Y. Gerasimov, Y.F. Maidanik, USSR Inventors Certificate 449213, 1974

[3] T.T. Hoang, T.A. O'Connell, J. Ku, C.D. Butler, T.D. Swanson, Miniature loop heat pipes for electronic cooling, in: International Electronic Packaging Technical Conference and Exhibition, vol. 2, Maui, Hawaii, 2003, pp. 517-525.

[4] P.A. Vityaz, S.V. Konev, V.B. Medvedev, V.K. Sheleg, Heat pipe with bidispersed capillary structures, in: Proceedings of the Fifth International Heat Pipe Conference, Tsukuba, Japan, 1984, pp. 127-135.

[5] S.V. Konev, F. Polasek, L. Horvat, Investigation of boiling in capillary structures, Heat Transfer Soviet Res. 19 (1) (1987) 14-17.

[6] N.S. Rasor, J.L. Desplat, K-max: a material with exceptional heat transfer properties, in: Proceedings of the 24th Intersociety of Energy Conversion Engineering Conference, vol. 6, Washington, DC, 1989, pp. 2847-2852.

[7] J.H. Rosenfeld, M.T. North, Porous media heat exchangers for cooling of highpower optical components, Opt. Eng. 34 (2) (1995) 335-341.

[8] M.T. North, J.H. Rosenfeld, R.M. Shaubach, Liquid film evaporation from bidisperse capillary wicks in heat pipe evaporators, in: Proceedings of the Ninth International Heat Pipe Conference, Albuquerque, NM, 1995, pp. 143147.

[9] M.T. North, D.B. Sarraf, J.H. Rosenfeld, Y.F. Maidanik, S. Vershinin, High heat flux loop heat pipes, in: Proceedings of the Sixth European Symposium on Space Environmental Control Systems, Noordwijk, The Netherlands, 1997, pp. 371-376.

[10] J. Wang, I. Catton, Vaporization heat transfer in biporous wicks of heat pipe evaporators, in: Proceedings of the Thirteen International Heat Pipe Conference, vol. 2, Shanghai, China, 2004, pp. 76-86. 
[11] E.G. Merilo, T. Semenic, I. Catton, Experimental investigation of boiling heat transfer in bidispersed media, in: Proceedings of the Thirteen International Heat Pipe Conference, vol. 2, Shanghai, China, 2004, pp. 87-93.

[12] T. Semenic, I. Catton, Boiling and capillary limit enhancement of a heat pipe wick using biporous wick capillary structure, in: Annals of the Assembly for International Heat Transfer Conference 13, Sydney, Australia, 2006, PRT-18 pages.
[13] S. Oktay, Departure from natural convection (DNC) in low-temperature boiling heat transfer encountered in cooling microelectronic LSI devices, in: Proceedings of the 7th International Heat Transfer Conference, vol. 4 Munich, Germany, 1982, pp. 113-118.

[14] S.J. Kline, F.A. McClintock, Describing uncertainties in single-sample experiments, Mech. Eng. 75 (1953) 3-9.

[15] D.C. Montgomery, Design and Analysis of Experiments, fifth ed., John Wiley \& Sons, New York, 2000. 218-276. 